\title{
Capsule Commentary on Marcum et al., Statin Dosing Instructions, Medication Adherence, and Low-Density Lipoprotein Cholesterol: a Cohort Study of Incident Statin Users
}

\author{
Patrick J. O'Connor, MA, MD, MPH \\ Health Partners Institute, Bloomington, MN, USA. \\ J Gen Intern Med 34(11):2585 \\ DOI: $10.1007 / \mathrm{s} 11606-019-05293-Z$ \\ (C) Society of General Internal Medicine 2019
}

\begin{abstract}
A pproximately 1 in 4 US adults are currently prescribed a statin, but many reports estimate that half of patients prescribed statins have suboptimal adherence. ${ }^{1}$ Complexity of the medication regimen contributes to medication nonadherence, and the majority of patients who take statins are on multiple other medications, often for the control of other cardiometabolic risk factors such as hypertension of type 2 diabetes mellitus. ${ }^{2}$ Nonadherence to statin therapy has been shown to increase mortality in some studies. ${ }^{3}$

Marcum et al. ${ }^{4}$ conducted a cohort study of incident statin users age 35 and over to ascertain whether prescribing statins in the evening versus morning is related to statin adherence, change in low-density lipoprotein (LDL) cholesterol levels, or proportion of patients achieving $\mathrm{LDL}<70 \mathrm{mg} / \mathrm{dL}$. In well-done analysis of data from 5099 study-eligible adults, they found no statistically or clinically significant differences in LDL levels or statin adherence that could be attributed to evening versus morning statin dosing, after adjustment in the analysis for potential confounders. Additional analyses that separately examined those taking simvastatin ( $72 \%$ with evening dosing) versus atorvastatin (70\% with morning dosing) also detected no significant differences in statin adherence, change in LDL, or achievement of $\mathrm{LDL}<70 \mathrm{mg} / \mathrm{dL}$ based on dosing instructions.

As noted by the authors, the cohort design precludes causal inference. However, the sizable number of study subjects, the mean follow-up period of 12 months for statin adherence and
\end{abstract}

19 months for changes in LDL, and the careful consideration of potential confounders in the analysis are strengths of this study. The results suggest that clinicians can be flexible in statin dosing instructions. If a patient prefers morning to evening dosing, or vice versa, such a preference can be accommodated knowing that the net effect on LDL will not be impaired, and that simpler dosing regimens are associated with better medication adherence.

Corresponding Author: Patrick J. O'Connor, MA, MD, MPH; Health Partners Institute, Bloomington, MN, USA (e-mail: Patrick.j. oconnor@healthpartners.com).

\section{Compliance with Ethical Standards:}

Conflict of Interest: The author declares that he/she does not have a conflict of interest.

\section{REFERENCES}

1. Grundy SM, Stone NJ, Bailey AL, et al. 2018 AHA/ACC/AACVPR/AAPA/ ABC/ACPM/ADA/AGS/APhA/ASPC/NLA/PCNA guideline on the management of blood cholesterol. J Am Coll Cardiol. 2018 November 3 (epub).

2. Kini V, Ho PM. Interventions to improve medication adherence: A review. JAMA 2018;320:2461-2473.

3. Ho PM, Magid DJ, Shetterly SM, et al. Medication nonadherence is associated with a broad range of adverse outcomes in patients with coronary artery disease. Am Heart J. 2008;155:772-779.

4. Marcum ZA, Hsaio-Ching H, Romanelli RJ. Statin dosing instructions, medication adherence, and low-density lipoprotein cholesterol: A cohort study of incident statin users. J Gen Intern Med (2019). https://doi.org/ 10.1007/s11606-019-05180-7.

Publisher's Note Springer Nature remains neutral with regard to jurisdictional claims in published maps and institutional affiliations. 